\title{
ACTIVITÉ DE FERMENTATION ET DE PROTÉOLYSE DE CERTAINES SOUCHES DE BACTÉRIES LACTIQUES EN PRÉSENCE D'ACIDES GRAS
}

\author{
par
}

\author{
S. POZNANSKI, A. SURAZYNSKI, Teresa d'OBYRN \\ Université d'Agriculture à Olsztyn (Pologne) \\ Chaire de la Technologie laitière \\ B. Habaj \\ Institut de l'Industrie laitière \\ Olsztyn-Kortowo (Pologne)
}

\section{Introduction}

Dans le processus de transformation du lait en ses dérivés avec la participation de la microflore, le cours régulier de la fermentation lactique et de l'hydrolyse des protéines joue le rôle principal. L'hydrolyse des protéines est effectuée surtout par l'extrait de présure et des enzymes protéolytiques qui sont dégagés par des cellules de bactéries lactiques (Amustad 1950, Van der Zant et Nelson 1953, Emmons 1962, Stadhouder 1962, Poznanski et coll. $1965 \mathrm{a}, 1965 \mathrm{~b}, 1965 \mathrm{c}$ et 1966$)$.

Kodicek et Worden (1945) remarquent que les acides oléique, linoléique et linolénique peuvent inhiber complètement la croissance du $L$. helveticus et la production d'acide lactique. D'après les mêmes auteurs, l'acide linoléique inhibe la prolifération de plusieurs souches de bactéries lactiques gram-positives.

Pourtant, Harman et Nelson (1955) ont constaté que des souches de Str. lactis pouvaient utiliser de grandes quantités d'acide oléique pendant leur prolifération, et il ressort du rapport de Foster et Nelson (1957) que les sels et les esters de l'acide oléique stimulaient le développement de plusieurs souches de bactéries lactiques, et surtout celles des genres Streptococcus et Lactobacillus.

Un peu plus tard, Andres et Jago (1964a et 1964b) démontrèrent que l'acide oléique inhibait la croissance et l'activité protéolytique de Str. cremoris C13, sans influencer du tout les souches de Str. lactis et de Str. diacetilactis.

$\mathrm{Au}$ cours de nos expérimentations actuelles nous avons étudié l'influence des teneurs basses en acide caprique et oléique sur le métabolisme de quelques souches de Str. lactis et de Str. diacetilactis qui se caractérisaient par leur résistance à la plupart des bactériophages rencontrés en Pologne. On a étudié les paramètres suivants : 
a) Apparence d'un caillé-présure acide;

b) Inhibition de la fermentation lactique ;

c) Inhibition de l'hydrolyse des protéines;

d) Influence de la présure sur la stimulation de la protéolyse;

e) Cinétique de la libération d'azote non-protéique pendant la coagulation du lait et de la $x$-caséine par la présure.

\section{Analyse}

On a étudié les souches suivantes de bactéries lactiques : Str. lactis 134 et 136, Str. diacetilactis 216 et 222 , la culture mixte de ces quatre souches, Str. themophilus $\mathrm{MK}^{10}, L$. helveticus XII, la culture mixte de ces deux souches, ainsi que $L$. bulgaricus, Str. thermophilus et le levain industriel à crème, pour l'activité de l'acidification. Les souches $134,136,216$ et 222 se caractérisaient par leur résistance aux bactériophages et possédaient quelques propriétés qui les distinguaient un peu des souches typiques de Str. lactis et Str. diacetilactis (Habaj, Poznanski et coll., 1966).

Les souches et leurs cultures mixtes furent examinées sur les milieux suivants :

1) Lait stérilisé (témoin).

2) Lait stérilisé additionné de 1,5 à $3 \mathrm{mM}$ d'acide caprique (dans 1 litre de lait).

3) Lait stérilisé additionné de 1,5 et $3 \mathrm{mM}$ d'acide oléique.

4) Lait stérilisé additionné de 1,5 et $3 \mathrm{mM}$ d'acide caprique et de la solution de présure dont les germes microbiens avaient été éliminés $(0,15 \mathrm{mg}$ à la concentration de $1: 90000 / 10 \mathrm{ml}$ de lait).

La solution de présure fut préparée en sérum physiologique et filtrée sur filtre Chamberland.

\section{Mode d'addition des acides gras au lait.}

Le lait centrifugé deux fois et additionné des quantités d'acides gras mentionnées auparavant, fut chauffé jusqu'à la température de $65-70^{\circ} \mathrm{C}$ et émulsifié pendant 2 minutes dans un dispositif spécial (à 3000 tours/min.).

Le mélange et le lait non additionné d'acide furent versés dans des éprouvettes en portions de $10 \mathrm{ml}$, stérilisés et incubés dans une étuve pendant 7 jours. L'addition d'acide gras, suivie de la stérilisation, fit baisser légèrement l'acidité du lait, comme on le voit dans le tableau I.

Des portions de lait de chaque combinaison furent ensemencées avec les souches examinées (5 p. 100) ou leurs cultures mixtes, précédemment obtenues dans du lait stérile. L'augmentation de l'acidité titrable était déterminée après 18 heures d'incubation à 
TABLEAU I

VARIATIONS DE L'ACIDITÉ DU LAIT (SUBSTRAT) APRìS ADDITION DËS ACIDES GRAS ET LA STÉRILISATION

\begin{tabular}{|c|c|c|c|c|c|}
\hline \multirow{3}{*}{$\begin{array}{c}\text { Acidité : } \\
\text { oD } \ldots \\
p \mathrm{H} \quad \ldots\end{array}$} & \multirow[t]{2}{*}{ Lait } & \multicolumn{2}{|c|}{ Lait + acide caprique } & \multicolumn{2}{|c|}{ Lait + acide oléique } \\
\hline & & $1,5 \mathrm{mM}$ & $3 \mathrm{mM}$ & $1,5 \mathrm{mM}$ & $3 \mathrm{mM}$ \\
\hline & $\begin{array}{c}16,2 \\
6,52\end{array}$ & $\begin{array}{r}19,1 \\
6,50\end{array}$ & $\begin{array}{c}20,3 \\
6,40\end{array}$ & $\begin{array}{c}18,6 \\
6,50\end{array}$ & $\begin{array}{r}19,6 \\
6,48\end{array}$ \\
\hline
\end{tabular}

la température optimum de chaque souche, l'activité protéolytique après 36 heures dans le substrat non additionné de présure, et après 7 jours dans le substrat additionné.

Dans ce dernier cas, il s'agissait de vérifier la possibilité de l'influence stimulante de l'enzyme hymosine sur l'activité des protéinases bactériennes (Poznanski et coll. 1965a).

\section{Méthodes}

L'augmentation de l'acidité titrable a été déterminée par la titration avec $0,05 \mathrm{n} \mathrm{NaOH}$. Les valeurs définitives furent calculées par la soustraction de l'acidité initiale des échantillons analogues du lait. Le $p \mathrm{H}$ était déterminé au moyen d'un $p$ H-mètre, avec l'électrode de verre et celle au calomel.

L'azote non protéique était dosé dans un sérum qu'on avait préparé par la précipitation des protéines du lait avec de l'acide trichloracétique, la concentration du mélange étant de 12 p. 100.

De chaque éprouvette incubée, on soustrayait les valeurs initiales de l'azote non protéique du lait, qui était préparé comme pour les échantillons examinés.

On observa aussi la cinétique de la libération de l'azote non protéique pendant la coagulation par la présure du lait frais et de la solution aqueuse de la $x$-caséine $(0,66$ p. 100). On l'avait obtenue par la méthode de Zittle et coll. (1963) en présence et en absence de $3 \mathrm{mM}$ d'acide caprique. La durée de la coagulation avait été fixée d'avance à 30 minutes.

\section{Résultats}

A) Apparence du caillé.

On remarqua que le lait additionné de $1,5 \mathrm{mM}$ d'acide caprique formait un caillé grenu, après incubation de 18 heures, avec les souches de Str. lactis 134 et 136. Str. diacetilactis 216 et 222 et leur 
TABLEAU II

INHIBITION DE LA FERMENTATION LACTIQUE PAR L'ACIDE CAPRIQUE

\begin{tabular}{|c|c|c|c|c|c|c|c|c|c|c|}
\hline \multirow{4}{*}{ No } & \multirow{4}{*}{ Souches microbiennes } & \multicolumn{8}{|c|}{ Sorte de milieu } & c \\
\hline & & \multicolumn{2}{|c|}{ Lait (témoin) } & \multicolumn{6}{|c|}{ L'acidité caprique ajoutée au lait } & \\
\hline & & \multirow[b]{2}{*}{$p \mathrm{H}$} & \multirow[b]{2}{*}{$\begin{array}{l}\text { Augmentation } \\
\text { de l'acidité } \\
\text { titrable en } \\
\text { p. } 100 \text { d'acide } \\
\text { lactique }\end{array}$} & \multicolumn{3}{|c|}{$1,5 \mathrm{mM}$} & \multicolumn{3}{|c|}{$3 \mathrm{mM}$} & \multirow[b]{2}{*}{ 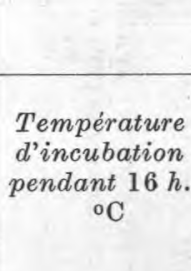 } \\
\hline & & & & $p \mathrm{H}$ & $\begin{array}{l}\text { Augmentation } \\
\text { de l'acidité } \\
\text { titrable en } \\
\text { p. } 100 \text { d'acide } \\
\text { lactique }\end{array}$ & $\begin{array}{c}\text { Inhibition } \\
\text { d'augmenta- } \\
\text { tion de l'aci- } \\
\text { dité en p. } 100\end{array}$ & $p \mathrm{H}$ & $\begin{array}{l}\text { Augmentation } \\
\text { de l'acidité } \\
\text { titrable en } \\
\text { p. } 100 \text { d'acide } \\
\text { lactique }\end{array}$ & $\begin{array}{l}\text { Inhibition } \\
\text { d'augmenta- } \\
\text { tion de l'aci- } \\
\text { dité en p. } 100\end{array}$ & \\
\hline 1 & Str. lactis $134 \ldots \ldots \ldots \ldots$ & 4,80 & 0,75 & 5,20 & 0,51 & 32,2 & 5,70 & 0,22 & 70,5 & 25 \\
\hline 2 & Str. lactis $136 \ldots \ldots \ldots \ldots$ & 4,95 & 0,71 & 5,40 & 0,42 & 40,5 & 5,95 & 0,22 & 68,8 & 25 \\
\hline 3 & Str. diacetilactis $216 \ldots \ldots$ & 5,35 & 0,74 & 5,65 & 0,56 & 32,9 & 5,95 & 0,27 & 63,1 & 25 \\
\hline $\begin{array}{l}4 \\
5\end{array}$ & $\begin{array}{l}\text { Str. diacetilactis } 222 \ldots \ldots \\
\text { Culture mixte de } 134,136\end{array}$ & 5,35 & 0,72 & 5,65 & 0,45 & 36,5 & 6,00 & 0,23 & 67,9 & 25 \\
\hline & $216,222 \ldots \ldots \ldots \ldots$ & 5,55 & 0,75 & 5,75 & 0,56 & 22,9 & 5,90 & 0,42 & 44,3 & 25 \\
\hline 6 & Lbc. helveticus XII ..... & 3,80 & 1,46 & 3,80 & 1,32 & 10,0 & 4,30 & 0,76 & 48,0 & 37 \\
\hline 7 & Str. thermophilus $\mathrm{MK}^{10} \ldots$ & 5,10 & 0,38 & 5,50 & 0,25 & 35,3 & 5,75 & 0,14 & 61,7 & 37 \\
\hline 8 & $\begin{array}{l}\text { Culture mixte de L. helveti- } \\
\text { cus XII et Str. thermo- }\end{array}$ & & & & & & & & & \\
\hline & philus $\mathbf{M K}^{10} \ldots \ldots \ldots \ldots$ & 4,45 & 0,65 & 4,75 & 0,48 & 26,8 & 5,55 & 0,21 & $4 \%, 7$ & 37 \\
\hline 9 & Lbc. bulgaricus $\ldots \ldots \ldots$ & 3,60 & 1,60 & 4,50 & 0,90 & 43,9 & 5,30 & 0,33 & 79,2 & 45 \\
\hline 10 & Str. thermophilus X..... & 5,15 & 0,58 & 5,30 & 0,25 & 56,6 & 6,40 & 0,12 & 78,7 & 45 \\
\hline 11 & Levain à crème .......... & 4,65 & 0,83 & 5,20 & 0,43 & 47,8 & 5,65 & 0,18 & 78,4 & 25 \\
\hline
\end{tabular}


culture mixte, la souche Str. thermophilus et le levain à crème. En présence de $3 \mathrm{mM}$ d'acide caprique, les mêmes souches n'étaient pas capables de former le caillé acide même après 36 heures d'incubation.

Le lajt additionné de 1,5 mM d'acide caprique, et incubé avec $L$. helveticus XII et $L$. bulgaricus eut un caillé inconsistant, tandis qu'en présence de $3 \mathrm{mM}$ du même acide on obtenait une consistance extrêmement grenue. Le lait additionné de 1,5 et $3 \mathrm{mM}$ d'acide oléique et ensemencé avec les mêmes souches et le levain à crème produisit un caillé de même apparence et consistance que celles du caillé formé du lait non additionné d'acides gras.

Los essais de la série suivante démontrèrent que les échantillons de lait additionnés d'acide caprique coagulaient beaucoup plus lentement que les témoins.

Après ineubation à $37^{\circ} \mathrm{C}$, la coagulation des témoins (échantillons non additionnẻs d'acide caprique) s'effectuait en 2 heures, tandis que des échantillons analogues additionnés de 1,5 mM d'acide caprique ne coagulaient qu'après 72 heures et leur caillé était inconsistant. Après l'addition de $3 \mathrm{mM}$ de même acide gras, la durée de la coagulation se prolongeait jusqu'à 96 heures.

Après incubation à $25^{\circ} \mathrm{C}$, les mêmes échantillons se comportaient de la manière suivante: le lait qui ne contenait pas d'acide caprique coagulait en 3 jours; celui additionné de 1,5 et $3 \mathrm{mM}$ du même acide ne eoagula pas par la présence même après 7 jours. Des échantillons additionnés d'acide caprique et de présure et incubé avec des monocultures et les cultures mixtes en question, coagulaient en 2 à 5 jours; cependant les caillés avaient une consistance de gruau.

\section{B) Inhibition de la fermentation lactique.}

Comme le tableau II l'indique, de toutes les souches examinées, e'est celle de $L$. helvéticus XII qui s'est montrée la moins sensible à la concentration donnée d'acide caprique, tandis que celles de L. bulgaricus, Str. thermophilus $\mathrm{X}$ ainsi que le levain à crème s'y sont montrées les plus susceptibles.

On a constaté que l'augmentation de l'acidité titrable dans des échantillons avec des souches diverses était plus variée pour la teneur en acide caprique de $1,5 \mathrm{mM}$ que pour la teneur de $3 \mathrm{mM}$. Il est intéressant de remarquer que les cultures mixtes des souches 134, 136, 216 et 222 et celle de L. helveticus XII et de Str. thermophilus $\mathrm{MK}_{10}$ ont été plus résistantes à la même concentration d'acide eaprique que ne le furent des souches individuelles.

Les mêmes quantités d'acide oléique n'inhibaient point la fermentation lactique d'une manière évidente. L'abaissement de l'augmentation de l'acidité titrable variait dans des limites de 1 à 2 p. 100 pour les deux niveaux d'acide oléique utilisés et pour les 
souches Str. diacetilactis 216 et 222 , la culture mixte des souches Str. lactis 134, 136, 216 et 222 et $L$. helveticus XII.

L'augmentation de l'acidité titrable dans des échantillons analogues incubés avec L. bulgaricus, Str. thermophilus X et le levain à crème fut réduite jusqu'à $16-17$ p. 100. L'acide oléique n'inhibait point la fermentation lactique des souches de Str. lactis 134, 136 et Str. thermophilus $\mathrm{MK}_{10}$.

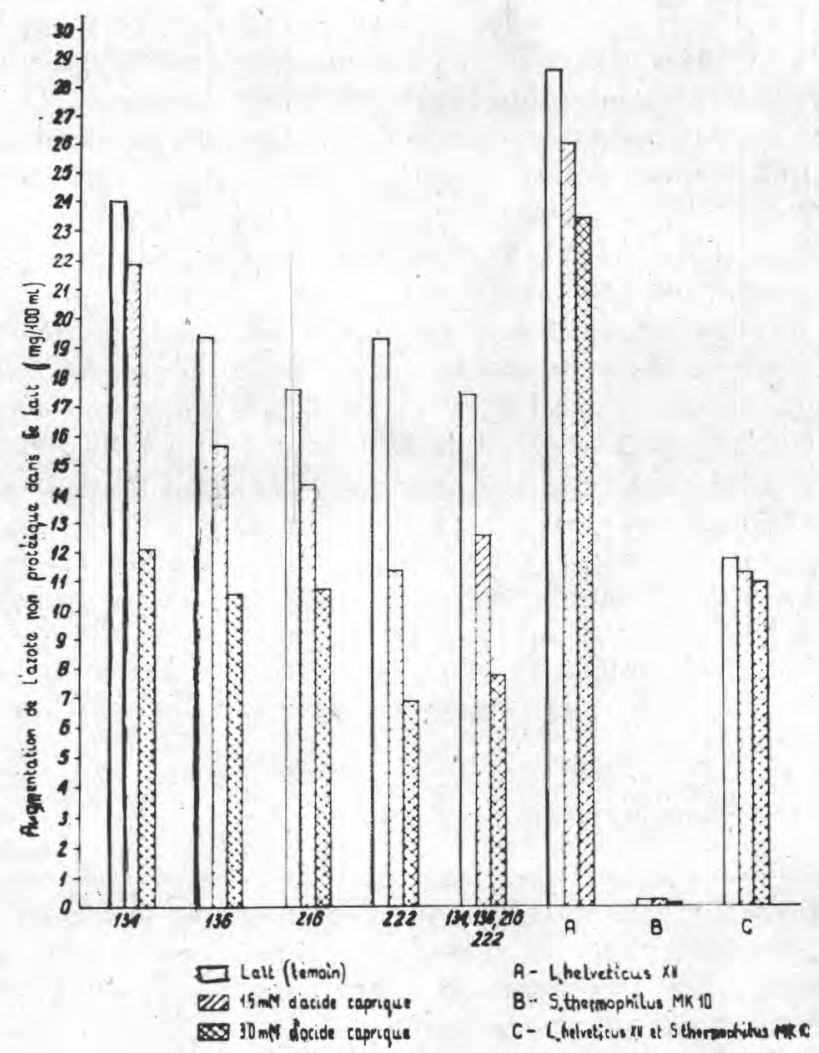

Fig. 1. - Influence de l'acide caprique sur l'activité protéolytique des bactéries lactiques

C) Inhibition de la protéolyse du lait.

Il ressort clairement du diagramme (fig. 1) que c'était $L$. helveticus qui se distinguait par l'activité protéolytique la plus grande, tandis que Str. thermophilus ne manifestait aucune aptitude à la dégradation des protéines du lait. La culture mixte de souches $L$. helveticus et Str. thermophilus $\mathbf{M K}_{10}$ ne révéla que de bien faibles aptitudes protéolytiques. L'augmentation de l'azote non protéique 
y était réduite de 60 p. 100 (28,7 p. 100 d'azote non protéique pour $L$. helveticus auprès de $18,8 \mathrm{mg}$ pour Str. thermophilus $\left.\mathbf{M K}_{10}\right)$.

Une activité protéolytique relativement élevée fut développée par les streptocoques mésophiles résistant aux bactériophages, 134, 136,216 et 222 et leur culture mixte. La souche 134 se montra la plus active.

C'étaient la souche de Str. diacetilactis 222 et la culture mixte des souches 134, 136, 216 et 222 dont l'hydrolyse des protéines du lait était inhibée le plus fortement pour les doses utilisées d'acide caprique.

La souche de $L$. helveticus XII et la culture mixte de $L$. helveticus et de Str. thermophilus $\mathrm{MK}_{10}$ - malgré l'activité protéolytique relativement basse de cette dernière - se montrèrent tout à fait insensibles à l'acide caprique. L'addition de $1,5 \mathrm{mM}$ inhibait aussi l'hydrolyse des protéines de lait par les souches 134, 136 et 216, mais seulement dans les limites de 9 à 20 p. 100 , tandis qu'en présence de $3 \mathrm{mM}$, l'inhibition atteignait $40-50$ p. 100 .

Le diagramme (fig. 2) nous permet de comparer l'intensité d'inhibition de l'augmentation d'acidité et celle de l'hydrolyse des protéines. En général, l'inhibition de l'augmentation d'acidité était plus élevée que celle de l'hydrolyse des protéines. C'étaient la souche de $L$. helvéticus XII, la culture mixte de $L$. helveticus et Str. thermophilus M10 et, à un certain point, Str. lactis 134 et. Str. diacetilactis 216 qui s'y distinguaient le plus.

L'activité protéolytique de la souche Str. diacetilactis 222 et celle de la culture mixte des quatre streptocoques $(134,136,216$

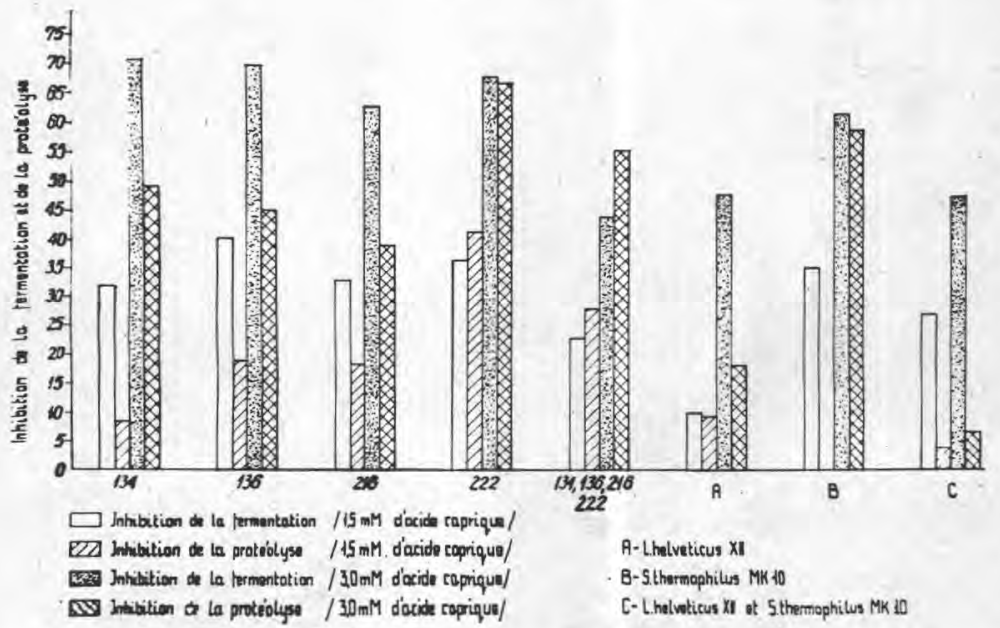

Fig. 2. - Inhibition de l'augmentation d'acidité et de l'hydrolyse des protéines du lait par l'acide caprique. 
et 222) étaient inhibées avec plus d'intensité que ne le fût l'augmentation de l'acidité.

De même que pour l'augmentation de l'acidité, l'acide oléique n'inhibait que bien faiblement l'activité protéolytique des souches $134,136,216,222$ et de leur culture mixte. La teneur en acide oléique de $3 \mathrm{mM}$ abaissa l'activité protéolytique de 2 à 5 p. 100. L'activité protéolytique de $L$. helveticus était inhibée par les deux concentrations d'acide oléique jusqu'à 15 p. 100 , celle de Str. thermophilus $\mathrm{MK}_{10}$ jusqu'à 28 p. 100, tandis que la culture mixte de ces deux souches jusqu'à 3 p. 100 seulement.

D) Influence de la présure sur la stimulation de protéolyse.

$\mathrm{Au}$ cours des expériences l'observation a été faite que l'activité protéolytique de la présure était, elle aussi, inhibée par l'acide caprique. Dans le lait additionné de présure et incubé à la température de $28^{\circ} \mathrm{C}$ pendant 7 jours, la réduction de l'azote non protéique libéré fut de 45 p. 100 en présence de 1,5 $\mathrm{mM}$ de l'acide caprique,

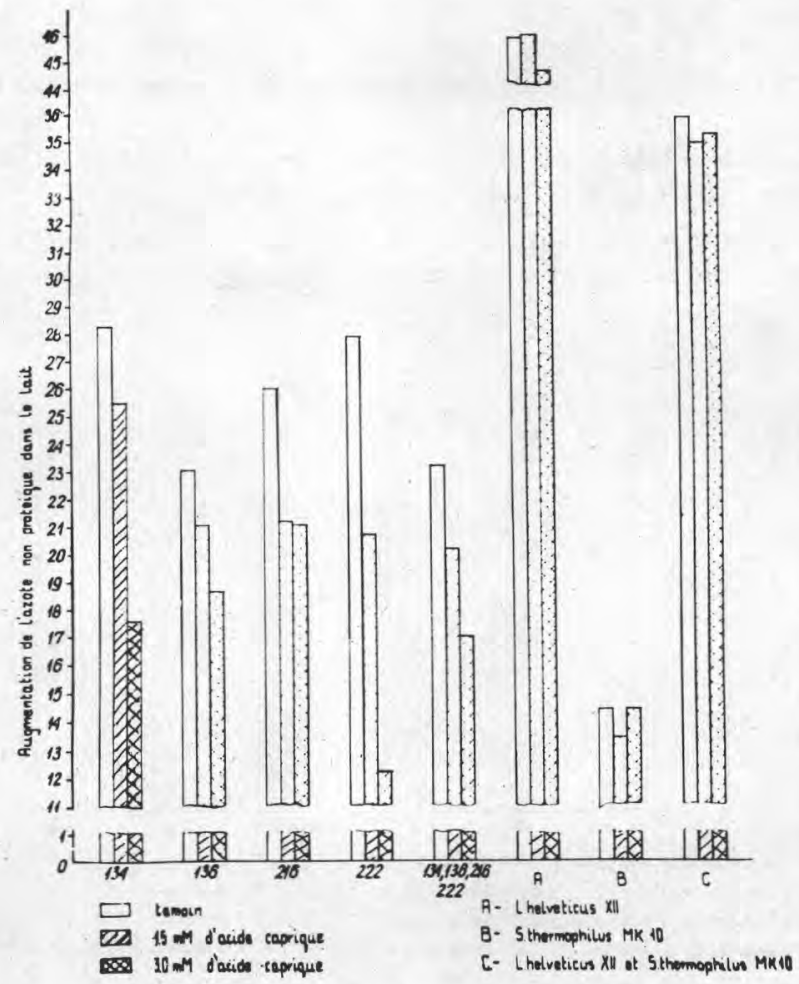

Fig. 3. - Effet stimulant de la présure sur l'activité protéolytique des bactéries lactiques en présence de l'acide caprique. 
et de 52 p. 100 pour la teneur en acide de $3 \mathrm{mM}$. A $37^{\circ} \mathrm{C}$, la réduction de l'activité protéolytique ne fut observée que pour la concentration de $3 \mathrm{mM}$. Elle atteignit 24 p. 100.

Le diagramme figure 3 représente l'activité protéolytique des souches en question en présence de la présure. Les valeurs indiquées expriment l'azote non protéique après la soustraction d'azote non protéique du lait de sortie et celui libéré par la présure elle-même. Dans ces conditions, la souche de $L$. helveticus XII révéla aussi l'aptitude protéolytique et l'insensibilité à l'acide caprique les plus élevées.

$A u$ cours des essais on remarqua que la présure exerce une influence évidemment stimulante sur l'activité de l'hydrolyse des protéines, par la souche de Str. thermophilus $\mathbf{M K}_{10}$, et surtout par la culture mixte de Str, thermophilus $\mathrm{MK}_{10}$ et de L. helveticus. Dans les deux cas on ne constata guère d'influence inhibitrice de la part de l'acide eaprique. La présence de la présure stimulait aussi plus ou moins l'activité protéolytique de Str. lactis 134 et 136, Str. diacetilactis 216 et 222 et la culture mixte de ces souches. Pourtant, contrairement à $L$. helveticus et Str. thermophilus, l'activité protéolytique des souches $134,136,216$ et 222 et de leur culture mixte était manifestement inhibée par l'acide caprique. De même que dans des essais avec des échantillons non additionnés de présure, Str. diacetilactis 222 s'y montra le plus sensible à l'acide caprique (1,5 mM d'acide diminuait l'augmentation de l'azote non protéique de 26 p. 100 , et $3 \mathrm{mM}$ de 56 p. 100). L'activité protéolytique des souches 134, 136 et 216 diminua dans des proportions de 10 à 18 p. 100 pour une teneur en acide caprique de $1,5 \mathrm{mM}$ et de 20 à $37 \mathrm{p}$. 100 pour la teneur de $3 \mathrm{mM}$.

E) Libération de l'azote non protéique pendant la coagulation du lait par la présure.

Une observation concernant la prolongation de la durée de coagulation du lait par la présure en présence d'acide caprique nous fit examiner la cinétique de l'augmentation de l'azote non protéique pendant la phase enzymatique de la coagulation. Comme substrat, nous avons employé du lait frais additionné de présure en quantité choisie pour le faire coaguler en 30 minutes (témoin). En même temps, une expérience analogue fut faite avec du même lait additionné de la même quantité de présure et de $3 \mathrm{mM}$ d'acide caprique. Les échantillons auxquels $3 \mathrm{mM}$ d'acide caprique avaient été ajoutés, ne coagulaient qu'après 90 minutes. Il ressort du diagramme (fig. 4), ei-contre, que le lait additionné d'acide caprique libérait beaucoup plus d'azote non protéique que le témoin. La courbe du lait additionné de $6 \mathrm{mM}$ d'acide caprique eut une apparence analogue. Cette observation nous semblant peu convaincante du point de vue théorique, nous décidâmes de répéter les 


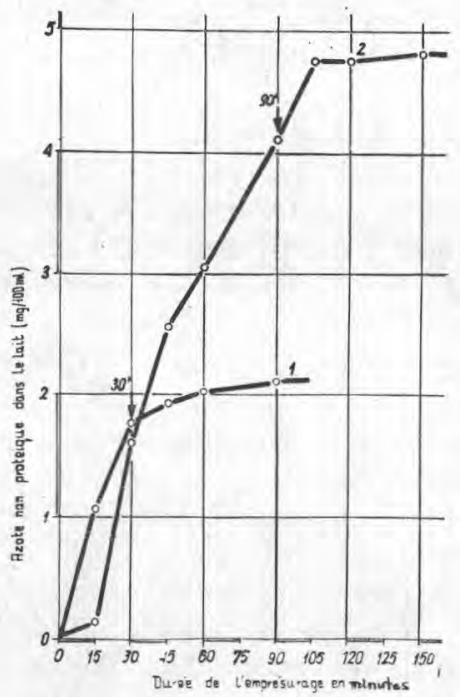

Fig. 4. - La durée de la coagulation et la libération de l'azote non protéique pendant la phase enzy-

- matique de l'action de la présure sur le lait.

1 - lait frais,

2 - lait frais additionné de $3 \mathrm{mM}$ de l'acide caprique.

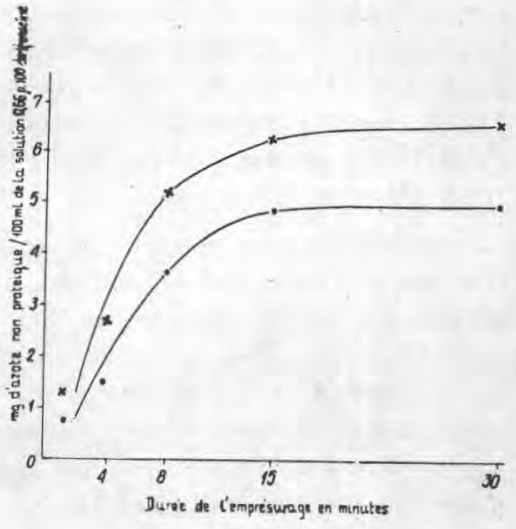

Fig. 5. - Libération de l'azote non protéique pendant la phase enzymatique de l'action de la présure sur la solution de $x$ caséine.

- - solution de $x$ caséine à 0,66 p. 100 non additionnée.

$\mathrm{x}$ - solution de $x$ caséine à 66 p. 100 additionnée de $3 \mathrm{mM}$ d'acide caprique.

essais avec la solution de $x$-caséine. Comme le montre le diagramme (fig. 5) l'augmentation de l'azote non protéique s'éleva encore cette fois. Cette observation exigera des recherches plus détaillées.

\section{Discussion}

Au contraire, des essais d'Anders et Jago (1964) ayant constaté l'influence inhibitrice de l'acide oléique sur la souche de Str. cremoris- $_{12}$, nos expériences ont montré que cet acide gras n'inhibait l'augmentation d'acidité de L. bulgaricus, Str. thermophilus X et de la culture de levain à crème, que d'une manière assez faible. Bien qu'on n'ait point constaté une influence inhibitrice de l'acide oléique sur l'augmentation d'acidité par $L$. helveticus XII et Str. thermophilus $\mathrm{MK}_{10}$, la diminution minime de l'activité protéolytique en a été pourtant observée. En général, l'influence de cet acide sur les souches examinées est insignifiante et elle n'a guère d'influence pratique.

L'acide oléique n'exerçait aucune influence sur les autres souches examinées, telles que Str. lactis et Str. diacetilactis, tandis que l'influence inhibitrice de l'acide caprique est confirmée par les 
études de Costilow et Speak (1951) sur la souche de Str. lactis H-1-10.

Bien que l'influence inhibitrice de l'acide caprique sur le métabolisme des souches $L$. Helveticus XII et Str. thermophilus MK $_{10}$ puisse être considérée comme minime, on ne doit pas négliger l'influence négative de cet acide sur la consistance des caillés produits.

Les études déjà mentionnées de Costilow et Speak (1951) indiquent que, parmi les acides gras saturés, l'acide caprylique, laurique et même myristique inhibent aussi la croissance de Str. lactis H-2-10. Il paraît done qu'il faille prévoir l'influence nuisible de ces quatre acides gras saturés au cas d'emmagasinage trop prolongé et non convenable du lait.

Dans le mélange fait quelquefois, du lait frais du matin, aussitôt après la traite, avec du lait du soir refroidi, ou bien avec du lait de vaches atteintes de mammite, on peut provoquer l'inactivation des lipases et la libération plus intense d'acide gras. Nous en trouvons la confirmation dans des essais de Bills et coll. (1964) d'où il ressort que la crème fraîche qu'on avait obtenue de lait avec un goût légèrement amer avait une teneur en ces quatre acides gras saturés trois fois plus élevée qu'en eût la crème de lait normal (895 $\mathrm{mg} / \mathrm{kg}$ auprès de $286 \mathrm{mg} / \mathrm{kg}$, dont l'acide caprique 139 auprès de 40$)$.

L'influence négative de l'acide caprique sur la consistance du caillé devrait être examinée avec plus de soins au cours de la sélection du lait destiné à la production des boissons de lait de toute sorte, où l'apparence du caillé décide tout d'abord de la qualité. Outre cela, la question se pose de savoir si l'épreuve de fermentation, jugée d'après les critères classiques, donne une apparence valable du caillé lorsqu'elle est faite sur du lait à lipolyse avancée.

Il faut aussi prendre en considération l'influence de ces acides gras saturés sur le procédé de fabrication et d'affinage des fromages. Comme nous l'avons exposé, des acides gras ajoutés au lait faisaient prolonger (en triple) la durée de la coagulation, au lieu de l'abréger, malgré l'augmentation d'acidité.

Il apparait que l'influence défavorable de ces quatre acides gras saturés sur le pouvoir coagulant du lait par la présure pourrait se manifester à condition que la teneur du lait en ces acides soit élevée.

Anders et Jago (1964) ont présenté l'hypothèse que les acides gras saturés pouvaient parfaitement diminuer l'activité des levains ainsi que l'hydrolyse des protéines pendant la production et l'affinage des fromages.

Bien que nos essais aient démontré l'influence stimulante de la présure sur l'hydrolyse des protéines par les souches examinées, l'effet inhibiteur de l'acide caprique sur Str. lactis 134, 136 et Str. 
diacetilactis 216 et 222 était encore si élevé qu'il faudrait tenir compte de ce phénomène au cours de la fabrication du fromage.

Il ressort encore des données d'Anders et Jago (1964) qu'un fromage âgé d'un mois contenait environ $75 \mu \mathrm{g} / \mathrm{g}$ d'acides gras, de $C_{8}$ jusqu'à $C_{12}$, ou $210 \mu \mathrm{g} / \mathrm{g}$ si l'on comprend l'acide myristique. Bills et Day (1965) en rapportent $390 \mu \mathrm{g} / \mathrm{g}$ dans un fromage affiné. L'action protéolytique de nos souches Str. lactis et Str. diacetilactis, ainsi que celle du levain à crème, que nous avons analysée ici, pouvait être sensiblement inhibée déjà dans la première phase de l'affinage.

Entre nos souches de streptocoques lactiques et la souche de Str. cremoris que Anders et Jago ont examinée (1964) il y a une telle différence que leur métabolisme n'était pas inhibé par l'acide oléique dont des quantités assez élevées se rencontrent aussi bien dans du lait à lipolyse bien avancée $(1843 \mu \mathrm{g} / \mathrm{g}$ de crème, Bills et coll., 1964) que dans le fromage (environ $373 \mu \mathrm{g}$ dans le fromage âgé d'un mois, Anders et Jago).

L'hydrolyse des protéines du lait par Str. helveticus XII et Streptococcus thermophilus $\mathrm{MK}_{10}$ n'était point inhibée par la présence des acides oléique et caprique, ce qui prouve que ces souches sont insensibles à la présence de ces acides dans le substrat. Au surplus, la culture mixte de ces deux souches thermophiles effectue, en présence de la présure, une hydrolyse intensive des protéines du lait additionné d'acide caprique et oléique.

\section{Résumé}

On a étudié l'influence des teneurs basses en acides caprique et oléique (1,5 et $3 \mathrm{mM}$ ) sur le métabolisme de quatre souches mésophiles de streptocoques lactiques, qui se distinguaient par leur résistance à la plupart des bactériophages. Pour comparer, on a examiné de même manière une souche active de $L$. helveticus XII, une souche peu active de Str. thermophilus et un levain à crème.

En observant l'augmentation de l'activité titrable on a constaté que la souche de $L$. helveticus XII se montrait la moins sensible aux concentrations appliquées de l'acide caprique, tandis que L. bulgaricus, Str. thermophilus $\mathrm{X}$ et le levain à crème manifestaient la plus grande sensibilité. Les cultures mixtes des quatre souches mésophiles et la culture mixte de $L$. helveticus XII et de Str. thermophilus $\mathrm{MK}_{10}$ étaient moins sensibles aux mêmes concentrations de l'acide caprique que ne l'étaient les souches individuelles.

On remarqua que des échantillons de lait additionnés de 1,5 mM d'acide caprique produisaient un caillé grenu après l'incubation avec des souches mésophiles, leur culture mixte, Str. thermophilus et le levain à crème. Ce phénomène n'était point observé dans des témoins et dans des échantillons additionnés d'acide oléique. 
Des doses appliquées de l'acide caprique inhibaient le plus vigoureusement l'hydrolyse des protéines par une souche mésophile (Str. diacetilactis 222) et la culture mixte de ces quatre souches.

$L$. helveticus et sa culture mixte avec Str. thermophilus $\mathrm{MK}_{10}$ se montrèrent évidemment résistants. En général, l'inhibition d'augmentation de l'acidité titrable par l'acide caprique était plus élevée que l'inhibition de l'hydrolyse des protéines. L'acide oléique n'influençait point pratiquement la fermentation et la protéolyse.

L'acide caprique inhibait aussi l'activité protéolytique de la présure elle-même. Bien que la présence de la présure stimulât l'activité protéolytique de la plupart des souches examinées, l'influence la plus faible de l'acide caprique était encore considérable. L'augmentation de l'azote non protéique pendant la phase enzymatique de la coagulation du lait et de la solution aqueuse de $x$-caséine, additionnée de $3 \mathrm{mM}$ d'acide caprique était plus élevée, et au surplus elle prolongeait en triple la durée de la coagulation.

\section{Summary}

Studies were made on the influence of low capric and oleic acid contents $(1,5$ and $3 \mathrm{mM})$ in milk on the metabolism of four mesophilic strains of lactis streptococei which distinguished themselves by their resistance to the most of bacteriophages. To compare, an active strain of $L$. helveticus XII, a less active strain of Str. thermophilus and a butter starter were examined in the same manner.

When observing the increase of titrable acidity, the strain of $L$. helveticus XII was found to be the least sensitive to capric acid in concentrations used, while $L$. bulgaricus and Str. thermophilus $\mathrm{X}$ as well as the butter starter, appeared to be the most sensitive ones. The mixed-strain cultures of four mesophilic strains and the mixed strain culture of $L$. helveticus XII and Str. thermophilus $\mathrm{MK}_{10}$ were less sensitive to the same capric acid concentrations than individual strains.

The samples to which $1.5 \mathrm{mM}$ of capric acid had been added formed a grany curd when incubated with the mesophilic strains, their mixed-Strain culture, Str. thermophilus and the butter starter. That phenomenon was observed neither in blank tests nor in samples to which oleic acid was added.

Protein hydrolysis by one mesophilic strain (Str. diacetilactis 222) and by the mixed-strain culture of those four strains were most vigourously inhibited by doses used of capric acid. L. helveticus and his mixed-strain culture with Str. thermophilus $\mathrm{KM}_{10}$ appeared to be remarkably resistant. In general, the inhibition of increased titrable acidity by capric acid was higher than that of protein hydrolysis. Neither fermentation nor proteolysis were practically influenced by oleic acid. 
Rennin proteolytic activity was also inhibited by capric acid: although the most of strains tested were stimulated in their proteolytic activity when rennin was present, the weakest influence of eapric acid was still considerable.

The increase of non protein nitrogen during the enzymatic phase of coagulation was higher in both milk and - case - in water solution when $3 \mathrm{~mm}$ of capric acid was added. Simultaneously the coagulation time was prolonged three times.

\section{RÉFÉRENCES BIBLIOGRAPHIQUES}

O. Amustad, 1950. Recherches sur l'activité protéolytique de la présure et de quelques bactéries lactiques notamment en ce qui concerne la maturation du fromage (en danois). Meddeland fran Statens Mejeriforsök Malmö, Lundgren Söners Boktr, 28, 1-170.

R. F. ANDers, G. R. JAgo, 1964a. The effect or fatty acids on the metabolism of lactic acid streptococci. I. Inhibition of bacterial growth and proteolysis. J. Dairy Res., 31, 81 .

R. F. ANDERS, G. R. JAGO, 1964 b. The effect of fatty acids on the metabolism of lactic acid streptococci. J. Dairy Res., 31, 91.

D. D. Bills, E. A. DAY, 1964. Determination of the major free fatty acids of cheddar cheese. J. Dairy Sci., 47, 733.

D. D. Bills, L. L. Khatri, E. A. Day, 1963. Method for the determination of the free fatty acids of milk fat. J. Dairy Sci., 46, 1342.

R. N. Costilow, M. L. SPECK, 1951. Inhibition of S. lactis in milk by fatty acids. J. Dairy Sci., 34, 1104.

D. B. Emmons, et al., 1962. Effect of strain of starter eulture and of manufacturing procedure on bitterness and protein breakdown in cheddar cheese. J. Dairy Sci., 45, 322.

E. M. Foster et al., 1957. Dairy Microbiology. Englewood eliffs, New Jersey, 81 .

B. Habaj, S. Poznanski et al., 1966. Effect of different strains of starter bacteria on the quality and the texture of edam cheese. XVII Congrès international de laiterie. Section $\mathrm{D}: 2,471$.

L. G. Harman, F. E. NeLson, 1955. Interrelationships of microorganisms in cream. J. Dairy Sci., 38, 1189.

E. KodICEK, A. N. WorDEN, 1945. The effect of unsaturated fatty acids on L. helveticus and other Gram-positive microorganisms. Biochem. J, 39, 78 .

S. Poznanski, J. Lenorr et G. Mocquot, 1965a. La protéolyse de la caséine par les enzymes intracellulaires de certaines bactéries. Le Lait, 441-442, 3.

S. Poznanski, J. Rymaszewski, 1965b. Proteolysis during the ripening of edam cheese with the participation of some bacteria strains. Part I. Changes in particular nitrogen fractions. Milchwiss., 20, 1. 14.

S. Poznanski, J, Rymaszewski, 1965c. Part II. Characteristics of N. P. N. Milehwiss, $20,8$.

S. Poznanski, B, HabaJ et al., 1966. Influence of different starter eultures on the protein breakdown in edam eheese. XVII ${ }^{e}$ Congrès international de laiterie, section $\mathrm{D}: 2,555$.

J. StAdHoUders, 1962. The proteolytic activity of rennet and starter bacteria in cheese with reference to bitter flavour. XVI ${ }^{e}$ Congrès international de laiterie, vol. B, 353 .

W. C. VAN DER ZANT, F. E. Nelson, 1953. Characteristies of an endocellular proteolytic enzyme system of S. lactis. J. Dairy Sci., 36, 1212.

C. A. Zitrle, J. A. Custer, 1963. Purification and some of the properties of $\alpha$-casein and $x$-casein. J. Dairy Sci., 46, 1183 . 